\title{
Digital-Native Trends in Teaching ESP to Engineering Students in Saudi Arabia
}

\author{
Abdul Wadood Khan ${ }^{1}$ \\ ${ }^{1}$ Department of English Language and Translation, College of Languages and Translation, King Saud \\ University, Riyadh, KSA \\ Correspondence: Abdul Wadood Khan, Department of English Language and Translation, College of Languages \\ and Translation, King Saud University, Riyadh, KSA.
}

Received: June 13, 2019 Accepted: August 4, 2019 Online Published: August 7, 2019

doi: 10.5539/elt.v12n9p13 URL: https://doi.org/10.5539/elt.v12n9p13

\begin{abstract}
The internet has redefined every aspect of human life-personal routines, business practices, and education. Advances in information and communication technology have also influenced English language learning and teaching in classrooms. This study explores the effectiveness of eLearning tools in teaching English for Specific Purposes (ESP) courses to engineering students in Saudi Arabia. To achieve the objectives of the study, a questionnaire with 15 questions about the employment of eLearning tools in Saudi universities was distributed to 60 ESP instructors selected from across universities in Saudi Arabia based on convenience sampling. The analysis of the data is inferential and interpretive. The results reveal that the adoption of eLearning tools in ESP classrooms is perceived by instructors to be effective for teaching the English language to engineering students. However, as per the result, eLearning tools along with traditional teaching methods are considered more convicing for teaching ESP to engineering students.
\end{abstract}

Keywords: ESP, eLearning tools, blended learning, trends in ESP

\section{Introduction}

The new millennium has witnessed a paradigm shift both in teaching and learning of English in Saudi Arabia. While studies conducted in the 1990s (Zaid, 1993, for example) indicated that most Saudis at that time had low motivation for learning English, today there are students who believe English to be much more important than Arabic. "English is superior to all other languages, including Arabic. Many young people have become keener to learn more English than Arabic as they feel that English is superior" (Jarf, 2008).

One consequence of this shift in attitudes has been the growth of English for Specific Purposes (ESP) courses in Saudi Arabian universities. English for Specific Purposes is a curriculum of English language skills for academic, professional, and business purposes; ESP courses aim to improve students' English language skill set in preparation for the professional world. English is now the predominant language of many academic fields, with an especially wide and sometimes compulsory usage in the fields of science, technology, engineering, and mathematics (STEM).

This study considers the effectiveness of technology in promoting the goals of ESP courses in Saudi Arabia. Thousands of students and instructors around the world today make use of Online Management Systems like Blackboard, WebCT, Online Learning, Moodle, and Nicenet in teaching all kinds of courses, including English as a Foreign Language (EFL) and ESP. In Saudi Arabia, this trend has been slower to come into effect, owing to the lack of proper IT environments, the lack of training for instructors in IT skills, and a lack of administrative support. However, there are professionals who are attempting to teach both language and literature using programs and apps like Moodle.

\subsection{English as a Medium of Instruction}

English is now essentially a worldwide lingua franca (Bamgbose, 2001), and its study serves a dual purpose for ESP learners, helping them to improve their English language proficiency and to acquire knowledge of their respective subjects.

As English tends, more and more, towards becoming a universal language, higher education curricula are becoming increasingly internationalized. In a context in which universities are ever competing to be recognized as 
world-league bodies, using English as a medium of instruction is crucial to achieving this goal. Universities around the world use English to rise to the standards of world-class institutions, aiming to empower students with knowledge that is at par with what is available at the best European and American universities, in a language that is general to all. The Gulf countries, home to native Arabic speakers have always had sections who have tried time and again to implement Arabic as the official medium of instruction through all levels of education, from elementary to tertiary, and across all disciplines, from language studies to engineering. This intervention has proven difficult, largely because a lack of English language proficiency would leave graduates of these countries out of touch with innovations in their respective fields. For this reason, according to one study, "the decision to revive Arabic as the language of instruction and scientific research has continually stirred debates among university-affiliated parties in the Gulf region" (Belhiah \& Elhami, 2015). Such a policy may have its advantages, in that it preserves Arabic culture and language as well as the confidence of the Arabic people. However, forward looking critics are right when they argue that the use of Arabic in the educational system is not practical (Olarte, 2009). English, used in so many different domains, must be learned because of its power of globalization. Only a few decades ago, countries like the USSR and China were content to use their native languages as the medium of instruction. In today's global environment, however, failing to master English means denying oneself access to the cutting edge of one's field as it is advanced through journal articles, conference papers, and textbook resources.

\subsection{An Innovative Method of Teaching English Language: Globalization to Glocalization}

Although English is being used as a tool of globalization, it is important to localize it to fit different contexts and purposes. Localized varieties of English, known in some contexts as pidgin and elsewhere by names specific to the context, such as Chinglish in China, work in the English for General Purpose context. These varieties are better suited to spoken English, however, than to the purposes of English Language courses and, particularly, English Language writing. Without a doubt, modified versions of English have their advantages in the business context. For chains like Starbucks, for example, the creation of local menus in different regions of the world is made possible only through these modified versions of the English language, which can be seen in countries such as Taiwan (Tsou, 2015) and Sweden (Typaldos, 2016). However, although the "glocalization" of English has its advantages in the business world, it does not work as well in the academic realm. It was for this reason that TESOL has proposed a standard for teaching ESP (Hastings, 2015). Such a standard ensures that academics do not fall into the habit of needless modification of the English language, and it also ensures a level playing field for professionals across the field, in which it is understood that concepts and vocabularies used in specific fields cannot be manipulated or compromised.

\subsection{Trends in Teaching ESP: The Role of Technology}

Among the various trends affecting the teaching of ESP courses, the role of technology cannot be over-emphasized. Technology has not yet replaced teachers, and it probably will not do so in the near future. However, as the trend develops it becomes increasingly clear that teachers who work with technology will soon replace teachers who do not, and rightly so. The internet has revolutionized all aspects of human life, including education, where its impact is increasingly felt throughout the educational system. The internet was born in 1980 and arrived at its current dominance beginning in 2008 with the advent of Facebook. The "social media decade" that followed witnessed new opportunities in various spheres, including education. The story of how the internet, social media platforms, and the invention of mobile applications have influenced ESP teaching and learning makes for interesting reading.

\subsubsection{Blended Learning}

In the Saudi context, developments in information and communication technology have influenced teaching and learning in English Language classrooms, and traditional means of teaching (face-to-face) are now blended with online learning. Content materials especially reflect these newer learning methods. ESP learners can now perform assigned tasks using technology. They can search the web and use e-books and beneficial software programs. Computer-assisted language learning (CALL) is a universal aid in teaching English language skills to ESP learners. Many ESP learners feel comfortable with these developments, believing that technology helps to conserve time and effort (Dashtestani \& Stojković, 2015). Nonetheless, as this study shows, students benefit when modern technology is combined with traditional ESP teaching methods.

\subsubsection{Mobile-Assisted Language Learning (MALL)}

If ESP learners already use smartphones in their everyday lives, why not bring phones into classrooms to aid their study of the English language? Mobile phones have proved their worth in the classroom by enabling the use of apps, online content, social media, and other resources in the service of language acquisition. A deep interest in mobile phone culture adds to students' interest and motivation. Although some ESP teaching experts argue that the use of smartphones in classrooms can be disruptive, if they are used correctly, mobile phones can be friends in the 
classroom rather than foes (Kirovska-Simjanoska, 2017). For example, an app termed 'Basic Engineering Dictionary' compiles a combination of engineering terms, equations, and formulas (Edutainment Ventures, 2017), making it easy for English for Engineering Purpose learners to have these resources at their fingertips.

\subsection{Research Questions}

This study aims to answer the following research questions:

1) Which eLearning tools do ESP instructors use in teaching engineering students in Saudi Arabia?

2) What is the percentage of engineering ESP instructors that use eLearning tools as teaching aids in classrooms?

3) Does the use of eLearning tools along with traditional teaching methods make for effective communication in ESP classroom?

\subsection{Hypothesis}

The researcher assumed a null hypothesis which is stated below:

Ho: The use of eLearning tools along with traditional teaching methods are not effective for teaching ESP to engineering students in the classroom.

\section{Literature Review}

\section{1 eLearning Tools for English Language Teaching}

While there is already a great deal of content created by ESP instructors, learners can benefit from a platform flooded by content created by themselves. Such a platform allows ESP learners to communicate with their peers without pressure. Continual trials ensure that learners eventually learn the skills they desire as they put new words and knowledge to use. The following tools, aids, and apps have assisted in achieving this objective.

Edmodo (2018): One of the most useful tools available today is Edmodo, a private micro-blogging service, available at www.edmodo.com, which provides a free and secure learning platform. Edmodo is very much like Facebook, though it is much more private and safer for a learning environment because it permits only teachers to create and manage accounts and only students who have a code to register in a group. The free app is accessible on any mobile device with internet capabilities, and it provides a simple way for teachers and students in a virtual class to connect and collaborate. Using this platform, teachers can send out quizzes and assignments, offer feedback, and receive completed assignments. They can also award grades, store and share content as files or links, maintain a class calendar, conduct polls, and send notes and text (SMS) alerts to individual students or to the entire class. Among the best features of Edmodo are the special accounts with which parents can view their children's homework assignments and due dates and receive updates on class and school events. Edmodo was recognized in 2011 by the American Association of School Librarians as one of the top 25 websites that foster the qualities of innovation, creativity, active participation, and collaboration in the category of 'Social Networking and Communication' (Kongchan, 2012). Also noted by the British Council as one of the best innovative trends for ESP learners in 2012 and 2017, Edmodo is popular among ESP teachers and students for the following reasons:

Facebook for classrooms: Language learning in classrooms can be conducted through fun and exciting activities. Imagine Facebook for ESP learners. The Edmodo interface is similar to other social media apps students already know. Today's learners want a platform on which they not only learn but also contribute. Students can contribute successfully while leaving their anxiety behind. It allows teachers to plan lessons and students to submit assignments. It assists with organization and functions as an extension of the classroom. Teachers and students use it to safely connect online, collaborate, post ideas, and send notes and messages (Stošić, 2015). It is considered an effective tool for raising the level of ESP learners' involvement in classroom activities (Sanders, 2012).

Benefits of chat and conferencing platforms: Chat and conferencing platforms on which ESP learners communicate in English are useful. Some studies have shown the benefit of chats and conferencing platforms in academic learning (Cheng, 2007; Lin \& Kuo, 2011). These platforms improve ESP learners' oral proficiency (Shamsudin \& Nesi, 2006). Shamsudin \& Nesi (2006) have demonstrated, also, that ESP learners' academic writing improved significantly when they used these social platforms. ESP learners experience less pressure when they use these platforms among their peers. With all these advantages, the platform has obvious advantages for engineering students learning ESP. Incidental learning, in which students learn even when they are not conscious of it, benefits ESP learners tremendously (Schmidt, 1993). The mobility of these platforms also breaks the traditional face-to-face classroom learning barrier (Sharpe \& Beetham, 2010).

Gamify: How about a game of learning new words, or one that lets students communicate in English within the specific context of their field? Such activities usefully expose students to actual word usage. Wordable, supported 
by Cambridge Dictionary, turns vocabulary learning into fun games for English language learners (Cambridge English, 2018). This can benefit ESP learners as well when particular sets of vocabulary are chosen. Moreover, it also features built-in repetitive and active-recall learning to help new words stick. Further, Civil Engineering Basics, which is not strictly an ESP learning tool, introduces users to the vocabulary using images and videos illustrating the actual usage of terms (Education Apps for Students, 2018). Apps like this can go a long way in improving English for Engineering Purposes (EEP) learners' vocabularies.

YouTube Videos and Podcasts: If content material reigns supreme, video content is even more so. If a picture is worth a thousand words, a video is worth perhaps a million. Students process the information in videos in a way that is natural to them. The British Council, for instance, has a wide variety of videos teaching the English language on the video-sharing platform YouTube and many more lessons available as podcasts. The materials have a wide range, from English-language-learning tips to core topics. Such resources boost immersive learning for ESP students both in and out of classrooms.

Interactive Whiteboard (IWB): The interactive whiteboard is the centre of focus in a classroom. Words can be introduced using graphics and images, so that instead of the teacher laboriously explaining what certain words mean, the meanings can be depicted clearly with the use of images and graphics. This is widely regarded as far more practical, considering that engineering is a practical and applied discipline rather than a theoretical one. Teachers can also bring real-life examples of building projects previously recorded or found on the internet to classrooms, which can partly fill in for field learning. Word-processing documents, spread sheets, digital images, and diagrams can be displayed on the IWB. The use of a great variety of materials and activities via the IWB leads to high levels of concentration, motivation, interactivity, and participation (Levy, 2002). An effective presentation of information, which aids memory and provokes thought, is achieved (Akbas \& Pektas, 2011).

Electronic Corpora: A large collection of authentic texts, a corpus is a targeted representation, usually available, these days, in an electronic format. Skilled use of corpora can expose students to vocabularies specific to their fields, helping ESP learners to learn to use technical words successfully (Fuentes, 2007). The use of corpora improves ESP learners' academic writing proficiency (Lee and Swales, 2006), which is particularly beneficial for aspiring engineers, who will have to write reports, project summaries, project progress reports, and so on. Working with a corpus is more useful for learning vocabulary than working with a dictionary. Yoon (2008) opined that corpora help students make fewer writing mistakes, enhancing not only their lexico-grammatical perception but their language awareness as well.

\subsection{Emerging Trends in ESP Teaching}

Translation Apps: Commercial establishments are constantly striving to open up their services to people from diverse backgrounds. Such efforts have resulted in the development of a number of translation apps. It is no longer surprising to see a tourist walk into a hotel and speak a completely foreign language to the receptionist. The speech gets translated by a smartphone app and an effective communication results that satisfy both the guest and the receptionist. Though the use of such apps for everyday needs is well recognized, their efficacy in ESP learning has not yet been fully perceived. Theoretically, these apps could benefit ESP students in environments where they have no personal interaction to verify the correctness of their sentence constructions. It is heartening to see software engineers attempting to make translation apps more applicable in diverse fields by developing apps that can understand language based on context (Capita Translation and Interpreting, 2018).

\subsection{Honourable Mentions}

Email subscription platforms like Grammar Girl and British Council YouTube offerings benefit ESP learners who sign up to receive weekly content. Topics including word usage, alternate spellings, grammar, sentence structure, and vocabulary are discussed. Constant exposure to English language usage can help ESP learners improve their language skills.

\section{Research Design}

The methodology for this study was designed to fulfil the research objectives. A well-formed questionnaire was designed for the data collection process. The questionnaire, which contained 15 questions about the use of eLearning tools in universities in Saudi Arabia, was distributed to 60 ESP instructors. The 15 questions were a combination of Likert items and closed and open-ended questions. ESP instructors were selected from universities across Saudi Arabia based on a convenience sampling method. The questions explored the effectiveness of the use of eLearning tools along with traditional teaching methods in engineering ESP classrooms. The results are represented in percentages and frequencies. The hypothesis was tested using the Pearson goodness-of-fit 
chi-square test. A p-value lesser than 0.05 is accepted at a $5 \%$ level of significance. The analysis of the data is inferential and interpretive.

\section{Results and Findings}

All of the participants who responded to the survey teach English for Specific Purposes to engineering students in Saudi Arabia. When asked questions about the eLearning tools they used in classrooms, instructors highlighted the following tools:

Table 1. eLearning tools used for teaching engineering students in ESP classrooms

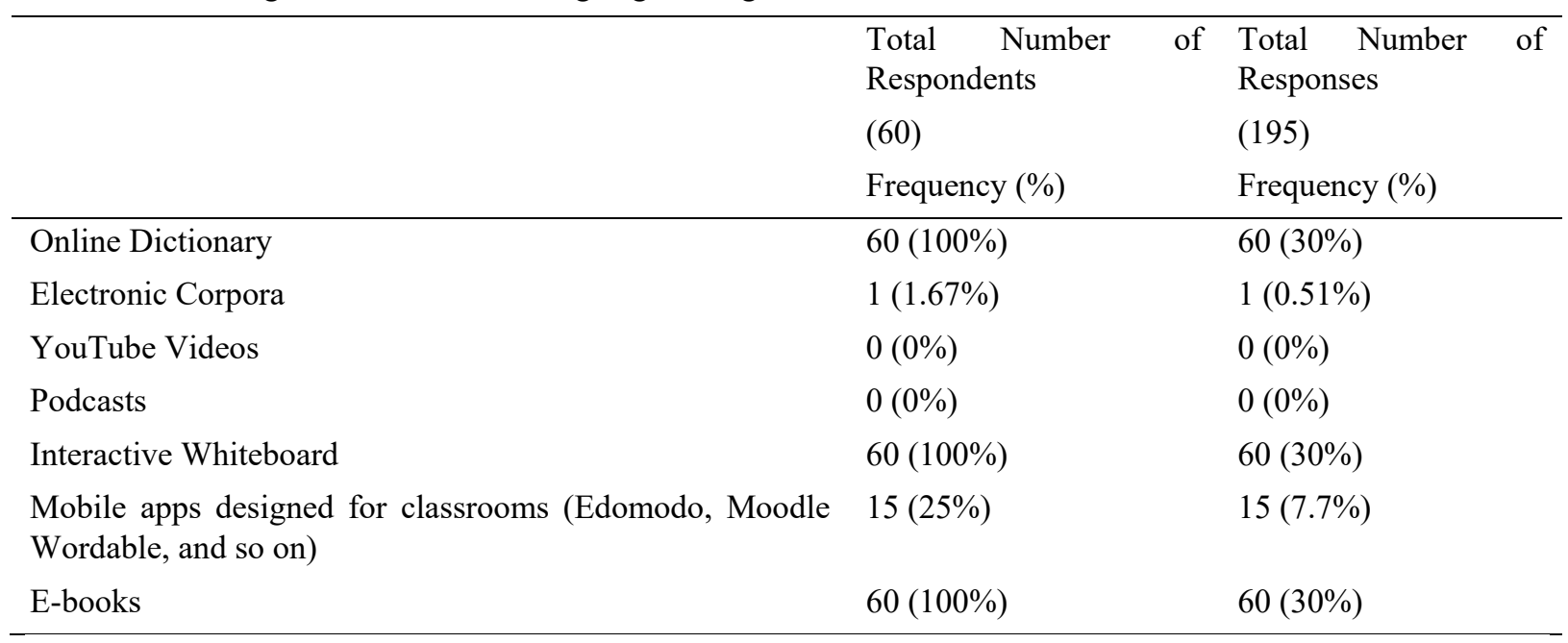

The results represented in Table 1 above confirm the observation by Khan and Adam (2016) that most, if not all, universities in Saudi Arabia have adopted the use of eLearning tools in classrooms across all disciplines. One of these learning tools is the Learning Management System (LMS), which is synonymous with the Interactive Whiteboard used in classrooms worldwide. Learning Management Systems (also known as Instructional Management Systems) are online collaboration and communication tools which allow administrators, teachers, and students to collaborate and communicate online in real-time across geographic distances. Some of the more popular commercial and open-source LMSs include Blackboard Learning System, Share-Point LMS, ANGEL Learning Management Suite, Sakai, and Moodle. Essentially, "LMSs provide eLearning courses through collaborative or stand-alone learning using numerous content formats and components, including media lectures, online classes, forums, assessment, and so on." (Lopes, 2014).

This technology is made available in most universities and colleges in Saudi Arabia by the Saudi Higher Education (HE). Even though it is being used widely in higher education institutions, some researchers believe it is not yet being exploited to its full potential. This is the opinion expressed by Hariri (2013) and Khan and Adam (2016), based on case studies conducted at King Fahad University of Petroleum and Minerals, (KFUPM) and Dammam Community College.

Of all these learning tools, however, the results showed that instructors have not extended the use of videos for teaching in classrooms. The use of videos explored through the Interactive Whiteboard is now extended to various additional online resources in the form of YouTube videos and podcasts. While YouTube videos are more popular, online audio publishing platforms, like Grammar girl (2019) offer podcast on English Language that can prove to be beneficial to students (Kavaliauskienė \& Anusienè, 2009).

While the corpora were hailed as an interesting invention in the 1960s, its use has dwindled over the past decades. The results of this study showed that none of the participants of the study $(0 \%)$ currently use electronic corpora. While the online dictionary is extremely useful, other eLearning tools might have replaced the use of the corpora, for example, mobile apps designed for use in classrooms. Although mobile apps are being used, it is evident that they are not being used to their full potential yet. Only $25 \%$ of the participants currently use mobile apps in classrooms (Sarré \& Whyte, 2017).

Learning vocabulary and organization of ideas forms a large part of ESP courses for engineering students. When asked if the use of mobile phones in classrooms enhances the learning capabilities of English language learners, 36 
respondents (75\%) stated that they allow students to use mobile phones in classrooms because of their perceived usefulness. The remaining $24(25 \%)$ opined that phones had a disruptive influence on students' learning, since students easily become distracted by them and may turn to games and chatting apps in the classroom.

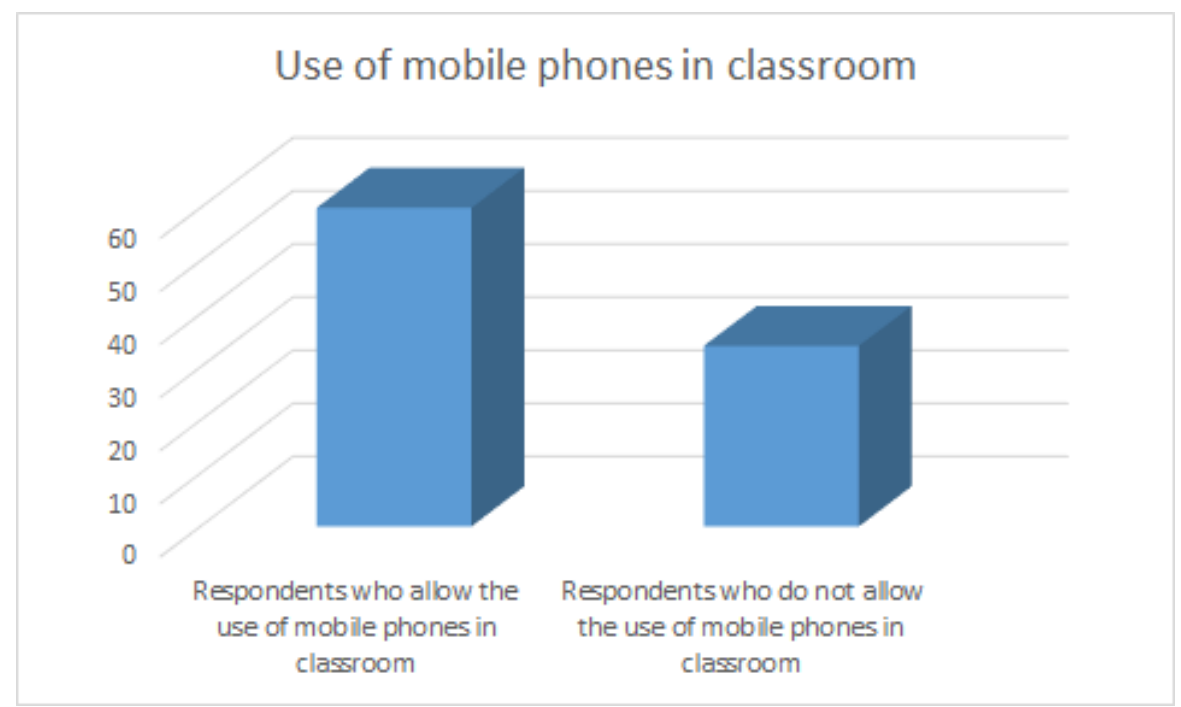

Figure 1. Use of mobile phones in ESP classrooms

The result depicted in Figure 1 indicates that most ESP instructors are interested in the use of mobile phones in classrooms. Mobile phones allow ESP instructors to introduce the use of online dictionaries, electronic corpora, and other beneficial apps for ESP learning (Kirovska-Simjanoska, 2017).

Respondents revealed that they found the use of both mobile-assisted learning and computer-assisted learning tools useful. The utility of these tools were accounted for based on the categories below:

Table 2. Advantages of eLearning tools over the traditional methods of teaching ESP to engineering students

\begin{tabular}{lll}
\hline & $\begin{array}{l}\text { Agree } \\
\text { Frequency (\%) }\end{array}$ & $\begin{array}{l}\text { Disagree } \\
\text { Frequency (\%) }\end{array}$ \\
\hline Interactive & $50(83.3 \%)$ & $10(16.7 \%)$ \\
Web-based & $40(66.7 \%)$ & $20(33.3 \%)$ \\
Mobile & $40(66.7 \%)$ & $20(33.3 \%)$ \\
Encourages visual learning & $50(83.3 \%)$ & $10(16.7 \%)$ \\
\hline
\end{tabular}

Most of the responses on the usefulness of eLearning tools over traditional learning methods are positive. Besides being novel, eLearning methods were considered more persuasive being extra visual and interactive form of learning. More than $80 \%$ of the respondents believe that the use of elearning methods makes for a more interactive method of teaching in classroom, compared to the traditional method. In like fashion, more than $80 \%$ of the respondents also perceived the learning method to be more appealing. More than half of the percentage of participants $(66.7 \%)$ believe that the usefulness of the app also lies in its ability to be mobile. The impression that it is web-based means that content is always accessible wherever and whenever students want them (Kučírková et al., 2014).

The hypothesis for this study was tested using the Pearson goodness-of-fit Chi-square test. The null hypothesis stated that: "The use of eLearning tools along with traditional teaching methods are not effective for teaching ESP to engineering students in the classroom." The participants responded to a Likert-type question which addressed their level of agreement or disagreement with the statement. The statistics of the responses are represented in the table below: 
Table 3. Respondents level of agreement or disagreement with the usefulness of eLearning tools used alongside traditional teaching methods

\begin{tabular}{llll}
\hline & Frequency & Chi-square value $\left(\mathrm{X}^{2}\right)$ & P-value at 5\% Significance Level \\
\hline Agree & 49 & 24.07 & $>0.00001$ \\
Disagree & 11 & & \\
\hline
\end{tabular}

Since all of the participants have adopted the use of eLearning tools in the classroom, the hypothesis was tested using Pearson goodness-of-fit chi-square for a one-sample population. The results of the Chi-square test shown in Table 3 are interpreted as follows. The chi-square test revealed a value of $X^{2}=24.07$. With a degree of freedom (df $=1$ ), $\mathrm{p}$ showed a value lesser than 0.00001 at a significance level of 0.05 . The null hypothesis is rejected. Conclusively, the research reports that the adoption of eLearning tools along with traditional teaching methods in ESP classrooms is effective for teaching English to engineering students. This result corresponds with the study conducted by Kučírková et al. (2014) which reported a positive effect on the use of web-based tools (Moodle) for teaching speaking, listening, and reading in English Language classrooms.

More and more teachers are adopting the use of eLearning tools as a teaching and learning device. The use of blended learning methods is continuously being championed across universities all over the world (Chirimbu \& Tafazoli, 2014). Since ESP is learner-cantered, there is a need to ensure that the chosen eLearning tools are the ones that are suggested and encouraged by students. On the other hand, it is important that the eLearning tools should be those that instructors are comfortable with, so that they may use it to its full potentials. eLearning tools are a practical and convenient way of teaching English Language to foreign learners. Ideally, both the students and teachers should be unanimous in the choice of a particular tool in order to exploit it to the maximum. The present generation of students, being the digital natives will, without doubt, have a lot of benefits to reap from the use of eLearning tools in classrooms. They believe that it saves time and effort. Hence, the use of eLearning tools motivates them to learn according to their objectives. The world is continually changing due to technological discoveries. It shapes our daily routine and has, inevitably, become a part of our life. The domain of English for Specific Purposes has also witnessed a ceaseless quest for technological innovation in the aspects of teaching and learning.

\section{Conclusion}

The usefulness of the eLearning tools mentioned above has been tested in the past and is continuing to be assessed. Overall, this study confirms that the development and use of education technology is moving forward in Saudi Arabia. Stakeholders at every level of education are developing clearer ideas about how the ever-changing dimensions of technology can and should be employed to promote the evolving priorities of the educational community.

The effectiveness of technology is helping engineering students learn the rudiments of ESP necessary not only for the attainment of their degrees but for success in their careers as well. This study concludes that eLearning tools are effective when incorporated with traditional teaching methods.

The teachers of this decade are witness to a very interesting phase in the history of education. The students, being digital natives, are all for technology, while the teachers, as digital immigrants (mostly) are now open to it now wary of it. This transitory psychological conflict will shortly pass away as there will soon be digital natives on both sides- the teacher and the taught.

\section{References}

Al Jarf, R. (2008). The Impact of English as an International Language (EIL) upon Arabic in Saudi Arabia. Asian EFL Journal.

Bamgbose, A. (2001). World Englishes and globalization. World Englishes, 20(3), 357-363. https://doi.org/ 10.1111/1467-971X.t01-1-00220

Beetham, H., \& Sharpe, R. (2010). Digital literacy framework. JISC - The Design Studio. Retrieved from http://jiscdesignstudio.pbworks.com/w/page/46740204/Digital\%20literacy\%20framework

Belhiah, H., \& Elhami, M. (2015). English as a medium of instruction in the Gulf: When students and teachers speak. Lang Policy, 14, 3-23. https://doi.org/10.1007/s10993-014-9336-9

Cambridge English. (2018). Wordable (Version 1.0.40). Retrieved from https://play.google.com/store/ apps/details?id $=$ co.playlingo. wordable\&hl=en 
Capita Translation and Interpreting. (2018). SmartMATE Machine Translation. Retrieved from https://www.capitatranslationinterpreting.com/smartmate/machine-translation/

Cheng, R. (2007). The role of computer-mediated communication in non-native speakers' acquisition of academic literacy (Doctoral dissertation, University of South Florida).

Chirimbu, S., \& Tafazoli, D. (2014). Blending Learning: Bridging the motivational Gap in ESP Courses. The $10^{\text {th }}$ International Scientific Conference eLearning and Software for Education. Bucharest.

Dashtestani, R., \& Stojkovic, N. (2015). The use of technology in English for specific purposes (ESP) instruction: A literature review. The Journal of Teaching English for Specific and Academic Purposes, 3(3), 435-456.

Edmodo, Inc. (2018). Edmodo (Version 9.12.9). Retrieved from https://play.google.com/store/apps/details?id= com.fusionprojects.edmodo\&hl=en

Education Apps for Students. (2018). Civil Engineering Basics (Version 1.10). Retrieved from https://play.google.com/store/apps/details?id=com.rrplayspot.civil.engineering.basics.site.notes

Edutainment Ventures. (2017). Basic Engineering Dictionary (Version 1.2.2) [Mobile application Software]. Retrieved from https://play.google.com/store/apps/details?id=com.ma.ld.dict.engg\&hl=en

Fester, B. (2017, January 21). Intelligent Tutoring Systems: What Happened? Retrieved from https://elearningindustry.com/intelligent-tutoring-systems-what-happened

Fuentes, A. C. (2007). Lexical acquisition in ESP via corpus tools: Two case studies. ScriptaManent, 3(1).

Grammar Girl (2019). Retrieved from https://www.quickanddirtytips.com/grammar-girl

Hariri, M. M. (2013). Effective use of LMS (Learning Management System) in teaching graduate geology course at KFUPM, Saudi Arabia. Paper presented at Fourth International Conference on the e-Learning Best Practices in Management, Design and Development of e-Courses: Standards of Excellence and Creativity. https://doi.org/10.1109/ECONF.2013.27

Hasting, C. (2015). Teaching English for Specific Purposes in Saudi Arabia. Baltimore, MD: TESOL Press.

Khan, R., \& Adam, C. (2016). Adoption of learning management systems in Saudi higher education context: Study at King Fahd University of Petroleum and Minerals \& Dammam Community College. SITE2016-Savannah, GA, United States, March 21-26, 2016.

Kavaliauskienè, G., \& Anusienè, L. (2009). English for Specific Purposes: Podcasts for listening skills. Santalka, 17(2), 28-37. https://doi.org/10.3846/1822-430X.2009.17.2.28-37

Kučírková, L., Kučera, P., \& Vydrová, V. (2014). English for specific purposes e-learning experimental research. ERIES Journal, 7(3-4). https://doi.org/10.7160/eriesj.2014.070306

Lee, D., \& Swales, J. (2006). A corpus-based EAP course for NNS doctoral students: Moving from available specialized corpora to self-compiled corpora. English for Specific Purposes, 25(1), 56-75. https://doi.org/ 10.1016/j.esp.2005.02.010

Levy, P. (2002). Interactive whiteboards in learning and teaching in two Sheffield schools: A developmental study. Retrieved November 23, 2008, from http://dis.shef.ac.uk/eirg/projects/wboards.htm

Lin, J., \& Kuo, C. (2011). Online peer conferencing in academic writing. The JALT CALL Journal, 7(2), 121-136.

Lopes, A. P. (2014). Learning Management Systems in higher education. Proceedings of EDULEARN14 Conference. Spain: Barcelona.

Olarte, O. (2009, August 25). ADEC Stresses on English as medium of instruction. Khaleej Times. Retrieved from https://www.khaleejtimes.com/article/20090824/ARTICLE/308249950/1002

Pektaş, H. M., \& Akbas, O. (2011). The effects of using an interactive whiteboard on the academic achievement of university students. Asia-Pacific Forum on Science Learning and Teaching, 12(2).

Sanders, K. S. (2012). An examination of the academic networking site Edmodo on student engagement and responsible learning (doctoral dissertation, ProQuest Dissertations \& Theses).

Sarré, C., \& Whyte, S. (2017). New developments in ESP teaching and learning research. https://doi.org/10.14705/rpnet.2017.cssw2017.9782490057016

Schmidt, H. G. (1993). Foundations of problem-based learning-Some explanatory notes. Medical Education, 27, 422-432. https://doi.org/10.1111/j.1365-2923.1993.tb00296.x 
Shamsudin, S., \& Nesi, H. (2006). Computer-mediated communication in English for specific purposes: A case study with computer science students at Universiti Teknologi Malaysia. Computer Assisted Language Learning, 19(4-5), 317-339. https://doi.org/10.1080/09588220601043164

Stošić, L. (2015). The importance of educational technology in teaching. International Journal of Cognitive Research in Science, Engineering and Education, 3(1).

Tsou, W. (2015). From globalization to glocalization: Rethinking English language teaching in response to the elf phenomenon. English as a Global Language Education (EaGLE) Journal, 1(1), 47-63.

Typaldos, C. (2016). Experiencing the Starbucks experience: A cultural analysis of the effects of glocalization (Unpublished master's thesis, Lund University, Scania, Sweden).

Yoon, H. (2008). More than a linguistic reference: The influence of corpus technology on L2 academic writing. Language Learning \& Technology, 12(2), 31-48.

Zaid, M. A. (1993). Comprehensive analysis of the current system of teaching English as a foreign Language in the Saudi Arabian intermediate schools. (Unpublished PhD, University of Colorado at Boulder: Boulder).

\section{Copyrights}

Copyright for this article is retained by the author(s), with first publication rights granted to the journal.

This is an open-access article distributed under the terms and conditions of the Creative Commons Attribution license (http://creativecommons.org/licenses/by/4.0/). 